\title{
Dynamic variability and seasonal predictability in an intermediate complexity coupled ocean-atmosphere model
}
C. S. Frederiksen ${ }^{1}$
J. S. Frederiksen ${ }^{2}$
R. C. Balgovind ${ }^{3}$

(Received 28 October 2012; revised 26 March 2013)

\begin{abstract}
We formulate a numerically efficient coupled ocean-atmosphere model. It consists of a global atmosphere and a Pacific basin ocean, with two dynamical levels in each component. The model has a realistic climatology and displays El Niño-Southern oscillation variability at the observed frequencies. In hindcasts over the period 1981 to 2000, the model displays good skill out to seven months in forecasting the tropical upper ocean temperatures and zonal current anomalies. The most skilful forecasts occur for those initialised during June to November. Skilful predictions for the atmospheric fields generally only extend to one month, but can be as much as three months during major El Niño-Southern oscillation events.
\end{abstract}

http://journal.austms.org.au/ojs/index.php/ANZIAMJ/article/view/6296 gives this article, (C) Austral. Mathematical Soc. 2013. Published May 10, 2013, as part of the Proceedings of the 16th Biennial Computational Techniques and Applications Conference. ISSN 1446-8735. (Print two pages per sheet of paper.) Copies of this article must not be made otherwise available on the internet; instead link directly to this URL for this article. 


\section{Contents}

1 Introduction

C35

2 Model details

2.1 Atmospheric model equations . . . . . . . . . . . . C37

2.2 Oceanic model equations . . . . . . . . . . . . . . C C40

2.3 Ocean-atmosphere coupling . . . . . . . . . . C C41

2.4 Computational methods . . . . . . . . . . . . . C42

3 Model climate and variability

$\mathrm{C} 43$

4 Model predictive skill

5 Conclusions

C51

References

C51

\section{Introduction}

Coupled ocean-atmosphere variability in the Pacific Ocean hemisphere associated with the quasi-periodic phenomenon known as El Niño-Southern oscillation (ENSO) is a major influence on global climate variations on seasonal to interannual time-scales [1]. ENSO is associated with global and regional scale atmospheric circulation [2,3] and rainfall variability [4]. Many different types of models of varying complexity have been proposed to model and/or forecast the essential dynamics and thermodynamics of ENSO. These include entirely statistical [5], dynamical prognostic ocean with diagnostic/statistical atmosphere $[6,7,8,9]$ and entirely dynamical $[10,11,12]$ models. The models vary from low resolution models with fairly simple physics and restricted domains [13] to comprehensive global coupled general circulation models (CGCMs). Palmer et al. [14] provided a description of models used in 
the DEMETER (development of a European multimodel ensemble system for seasonal to inTERannual prediction).

Jin et al. [15] evaluated the current status of ENSO prediction in comprehensive CGCMs in the datasets of the APPC/CliPAS (APEC climate center/climate prediction and its application to society [16]) and DEMETER projects. They concluded that most of the models have problems in reproducing the mean and mean annual cycle of the sea surface temperature (SST) over the period 1980 to 2001. Consequently, the interannual variability in the SST was not well reproduced, with discrepancies becoming worse with increasing lead time. They also found that these models performed best during the growth phase of extreme ENSO events and not so well in the decay phase. The models had little skill during ENSO-neutral periods. In line with the concept of a boreal spring predictability barrier, they also found that the skill of the models reduced more quickly with time for forecasts initiated during February or May, when compared to those initiated in August or November.

In the last decade, a lot of effort has gone into the design of ensemble seasonal prediction methods to improve dynamical forecasts of ENSO. Our aim in this paper is to develop a computationally efficient coupled ocean-atmosphere model of intermediate complexity, suitable for investigating different methods of ensemble prediction initialisation, even for large ensemble sizes, in a reasonable time and at low resolution. Here, we formulate the model and outline its behaviour and predictive skill. In an accompanying paper [17], we use the model to develop and test a new method of ensemble initialisation.

The plan of the article is as follows. In Section 2, the model formulation and computational methods are discussed. In Section 3, the model climate and variability is evaluated; in Section 4, the predictive skill in forecasting ENSO variability is assessed. Our conclusions are in Section 5. 


\section{Model details}

The model outlined here has a global atmosphere coupled to a Pacific basin ocean extending from $90^{\circ} \mathrm{S}$ to $90^{\circ} \mathrm{N}$, as shown in Figure 1, and with no through flow in the Southern Ocean. The resolution of both components corresponds to a model grid of circa $2.3^{\circ}$ latitude and $3.75^{\circ}$ longitude. The final choice of model parameters, for example, the diffusion and surface drag coefficients, were determined from a parameter study to best simulate ENSO variability.

\subsection{Atmospheric model equations}

The atmosphere in the model consists of two pressure levels, $250 \mathrm{hPa}$ and $750 \mathrm{hPa}$. Prognostic equations are specified for both the streamfunction and potential temperature at these levels, but the vertically averaged flow is assumed to be non-divergent. Thus, there are five prognostic variables in the model, $\psi, \tau, \chi, \theta$ and $\sigma$, representing the vertical average (or mean) streamfunction, the shear streamfunction, the shear velocity potential (or the lower level velocity potential), and the mean and shear potential temperature, respectively. The governing equations are

$$
\begin{aligned}
\frac{\partial \nabla^{2} \psi}{\partial \mathrm{t}}= & -\mathrm{J}\left(\psi, \nabla^{2} \psi+2 \mu+\frac{1}{2} \mathrm{~h}\right)-\mathrm{J}\left(\tau, \nabla^{2} \tau-\frac{1}{2} \mathrm{~h}\right)+\mathrm{J}\left(\chi, \nabla^{2} \chi\right) \\
& +\nabla \cdot\left[\left(\nabla^{2} \tau-\frac{1}{2} \mathrm{~h}\right) \nabla \chi\right]+\nabla \cdot\left(\nabla^{2} \chi \nabla \tau\right)-\mathrm{K} \nabla^{2}(\psi-\tau) \\
& +\mathrm{K}_{2} \nabla^{2}\left(\nabla^{2} \psi+2 \psi / \mathrm{a}^{2}\right) \\
\frac{\partial \nabla^{2} \tau}{\partial \mathrm{t}}= & -\mathrm{J}\left(\psi, \nabla^{2} \tau-\frac{1}{2} \mathrm{~h}\right)-\mathrm{J}\left(\tau, \nabla^{2} \psi+2 \mu+\frac{1}{2} \mathrm{~h}\right) \\
& +\nabla \cdot\left[\left(\nabla^{2} \psi+2 \mu+\frac{1}{2} \mathrm{~h}\right) \nabla \chi\right]+\mathrm{K} \nabla^{2}(\psi-\tau) \\
& +\mathrm{K}_{2} \nabla^{2}\left(\nabla^{2} \tau+2 \tau / \mathrm{a}^{2}\right),
\end{aligned}
$$



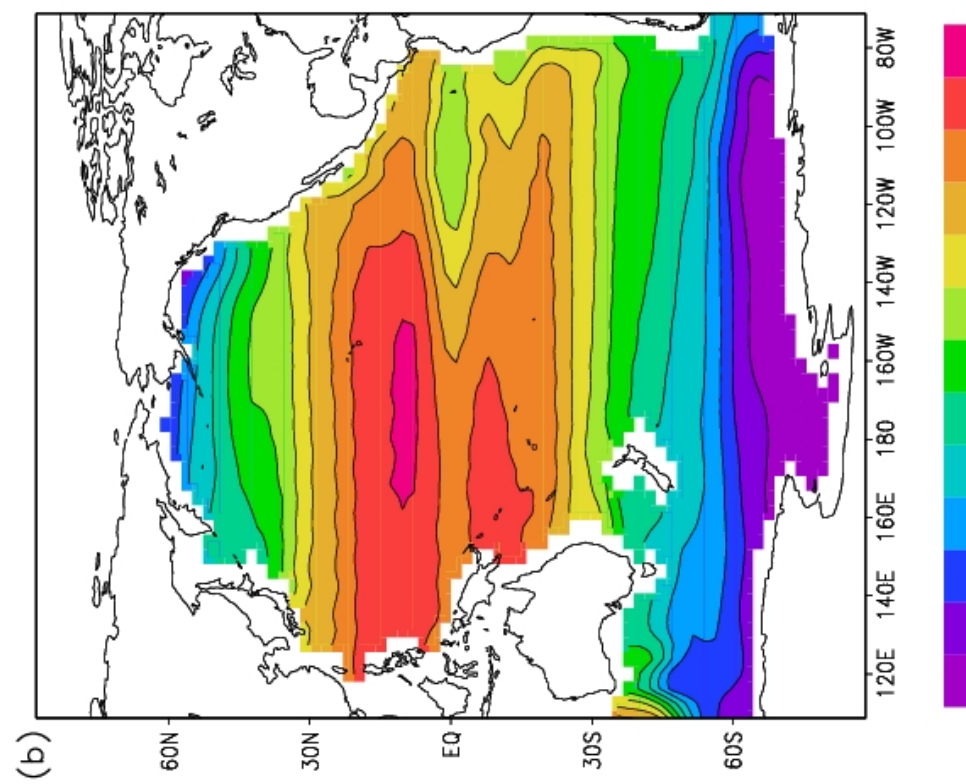

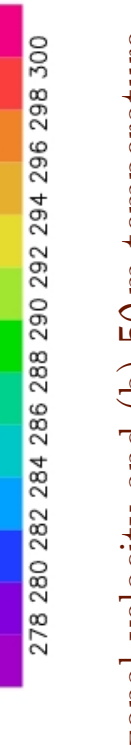

ב⿱

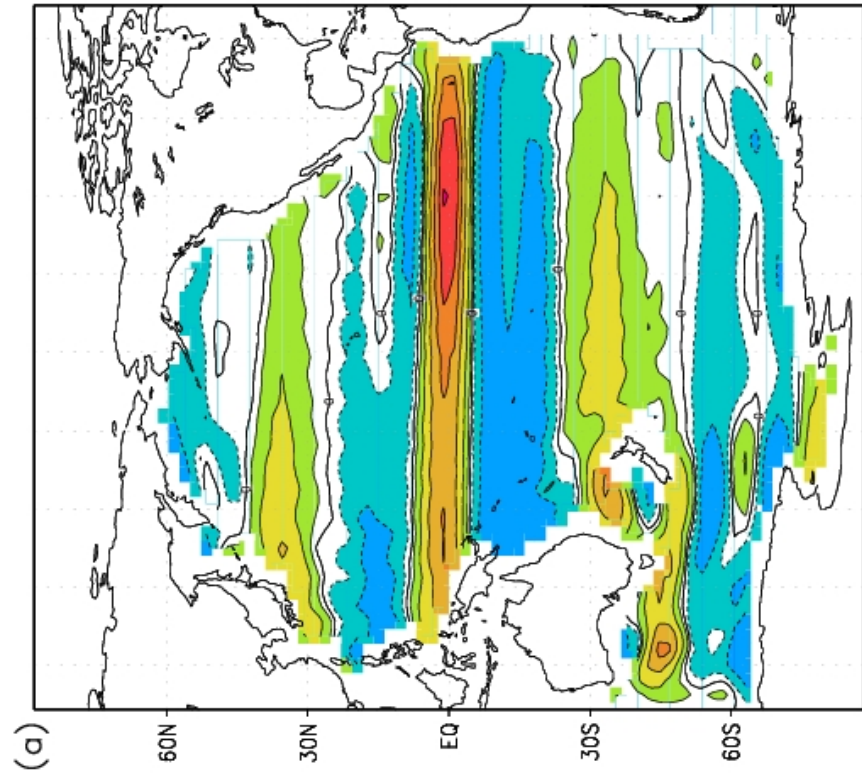

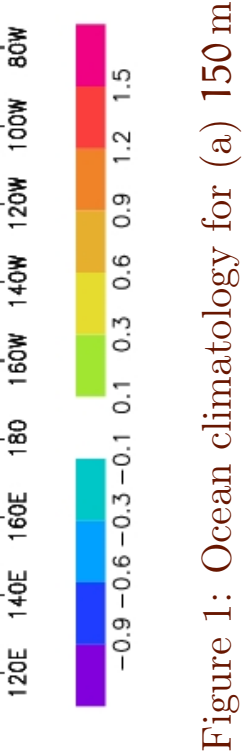




$$
\begin{aligned}
\frac{\partial \nabla^{2} \chi}{\partial \mathrm{t}}= & -\mathrm{J}\left(\chi, \nabla^{2} \psi+2 \mu+\frac{1}{2} \mathrm{~h}\right)-\nabla \cdot\left[\left(\nabla^{2} \psi+2 \mu+\frac{1}{2} \mathrm{~h}\right) \nabla \tau\right] \\
& -\nabla \cdot\left[\left(\nabla^{2} \tau-\frac{1}{2} \mathrm{~h}\right) \nabla \psi\right]+\nabla^{2}\left[\nabla \psi \cdot \nabla \tau-\mathrm{J}(\psi, \chi)+\mathrm{c}_{\mathrm{p}} B \theta\right] \\
& -\mathrm{K} \nabla^{2} \chi+\mathrm{K}_{2} \nabla^{2}\left(\nabla^{2} \chi+2 \chi / \mathrm{a}^{2}\right), \\
\frac{\partial \theta}{\partial \mathrm{t}}= & -\mathrm{J}(\psi, \theta)-\mathrm{J}(\tau, \sigma)+\nabla \cdot \sigma \nabla \chi-s \nabla^{2} \chi \\
& +\mathrm{K}_{2} \nabla^{2} \theta+\alpha\left(\theta_{\mathrm{E}}-\theta\right)+\mathrm{H}_{\mathrm{a}}, \\
\frac{\partial \sigma}{\partial \mathrm{t}}= & -\mathrm{J}(\psi, \sigma)-\mathrm{J}(\tau, \theta)+\nabla \cdot \theta \nabla \chi+\mathrm{K}_{2} \nabla^{2} \sigma+\alpha\left(\sigma_{\mathrm{E}}-\sigma\right),
\end{aligned}
$$

where

$$
J(A, B)=\left(\frac{\partial A}{\partial \lambda} \frac{\partial B}{\partial \mu}+\frac{\partial A}{\partial \mu} \frac{\partial B}{\partial \lambda}\right)
$$

is the Jacobian. Here, $\lambda$ is longitude and $\mu$ is the sine of latitude. Topography is incorporated in the term $h=2 \mu \mathrm{gH} /\left(\mathrm{RT}_{\mathrm{o}}\right)$, and enters the atmospheric component as a source of vorticity and divergence. Here, $\mathrm{g}=9.8 \mathrm{~ms}^{-2}$ is gravity, $\mathrm{H}$ is the actual global topography, $\mathrm{R}=287 \mathrm{JK}^{-1}$ is the gas constant for air, $\mathrm{T}_{\mathrm{o}}=273 \mathrm{~K}$ is the horizontally averaged surface temperature, $\mathrm{K}=$ $2.3148 \times 10^{-6} \mathrm{~s}^{-1}$ is a surface drag coefficient, $\mathrm{K}_{2}=2.5 \times 10^{5} \mathrm{~m}^{2} \mathrm{~s}^{-1}$ is a diffusion coefficient, $\mathrm{a}=6.37 \times 10^{6} \mathrm{~m}$ is the radius of the earth, $\mathrm{c}_{\mathrm{p}}=1004 \mathrm{JK}^{-1} \mathrm{~kg}^{-1}$ is the specific heat of dry air at constant pressure, and $B=0.124$ is a dimensionless constant. Convection is incorporated in the term $-s \nabla^{2} \chi$, with $\mathrm{s}=\mathrm{Q}_{\mathrm{F}} \mathrm{q}$ where $\mathrm{q}$ is the specific humidity at the lower level, and $\mathrm{Q}_{\mathrm{F}}$ is an effective convective heating parameter, here set to $1000 \mathrm{~K}$.

Radiative forcing of the general circulation is parameterised as a relaxation of the mean and shear potential temperatures, $\theta$ and $\sigma$, respectively, to their climatological annual cycle, $\theta_{\mathrm{E}}$ and $\sigma_{\mathrm{E}}$, for the period 1951-2000. The relaxation coefficient $\alpha$ is set to $5.787 \times 10^{-6} \mathrm{~s}^{-1}$. An additional heating term $\mathrm{H}_{\mathrm{a}}$ is related to the vertical heat flux between the ocean and atmosphere and is described when we consider the ocean-atmosphere coupling. 


\subsection{Oceanic model equations}

The oceanic model is also formulated in terms of vorticity, divergence and temperature, and assumes the Boussinesq approximation. It consists of two vertical levels, at $50 \mathrm{~m}$ and $150 \mathrm{~m}$ depths, with an assumed non-divergence level at $100 \mathrm{~m}$. An abyssal layer, with upper boundary at $250 \mathrm{~m}$, is connected to the two levels through diffusion. An abyssal temperature of $287.5 \mathrm{~K}$ is assumed between $30^{\circ} \mathrm{S}$ to $30^{\circ} \mathrm{N}$ and a zonally symmetric temperature profile, based on data from Levitus [18], is used outside this region. An apparent ocean temperature $\left(T-T_{0}^{*}\right)$ is used, relative to a reference temperature $\mathrm{T}_{\mathrm{o}}^{*}=283.5 \mathrm{~K}$, where $\mathrm{T}$ is the actual temperature. The equation of state used is then $\rho=\rho_{0}\left[1-\alpha_{0}\left(T-T_{0}^{*}\right)\right]$. Here, $\rho$ is density, $\rho_{o}=1000 \mathrm{kgm}^{-3}$ is a reference density for water, and $\alpha_{0}=2 \times 10^{-4} \mathrm{~K}$ is the thermal expansion coefficient for water. The ocean model is formulated for the five prognostic variables $\psi_{0}, \tau_{0}, \chi_{0}, \theta_{0}$ and $\sigma_{0}$, representing the mean streamfunction, the shear streamfunction, the lower level velocity potential, and the mean and shear apparent temperature, respectively. The governing equations are

$$
\begin{aligned}
\frac{\partial \nabla^{2} \psi_{\mathrm{o}}}{\partial \mathrm{t}}= & -\mathrm{J}\left(\psi_{\mathrm{o}}, \nabla^{2} \psi_{\mathrm{o}}+2 \mu+\frac{1}{2} \mathrm{~h}_{\mathrm{o}}\right)-\mathrm{J}\left(\tau_{\mathrm{o}}, \nabla^{2} \tau_{\mathrm{o}}-\frac{1}{2} \mathrm{~h}_{\mathrm{o}}\right) \\
& +\mathrm{J}\left(\chi_{\mathrm{o}}, \nabla^{2} \chi_{\mathrm{o}}\right)+\nabla \cdot\left[\left(\nabla^{2} \tau_{\mathrm{o}}-\frac{1}{2} \mathrm{~h}_{\mathrm{o}}\right) \nabla \chi_{\mathrm{o}}\right] \\
& +\nabla \cdot\left(\nabla^{2} \chi_{\mathrm{o}} \nabla \tau_{\mathrm{o}}\right)+\frac{\mathrm{p}_{\mathrm{o}} \mathrm{K}}{4 \rho_{\mathrm{o}} \mathrm{g} \Delta z} \nabla^{2}(\psi-\tau)+\mathrm{K}_{6} \nabla^{8} \psi, \\
\frac{\partial \nabla^{2} \tau_{\mathrm{o}}}{\partial \mathrm{t}}= & -\mathrm{J}\left(\psi_{\mathrm{o}}, \nabla^{2} \tau_{\mathrm{o}}-\frac{1}{2} \mathrm{~h}_{\mathrm{o}}\right)-\mathrm{J}\left(\tau_{\mathrm{o}}, \nabla^{2} \psi_{\mathrm{o}}+2 \mu+\frac{1}{2} \mathrm{~h}_{\mathrm{o}}\right)+\mathrm{K}_{6} \nabla^{8} \tau_{\mathrm{o}} \\
& -\frac{\mathrm{k}_{2}}{2(\Delta z)^{2}} \nabla^{2} \tau_{\mathrm{o}}+\nabla \cdot\left[\left(\nabla^{2} \psi_{\mathrm{o}}+2 \mu+\frac{1}{2} \mathrm{~h}_{\mathrm{o}}\right) \nabla \chi_{\mathrm{o}}\right] \\
& +\frac{p_{\mathrm{o}} \mathrm{K}}{4 \rho_{\mathrm{o}} \mathrm{g} \Delta z} \nabla^{2}(\psi-\tau),
\end{aligned}
$$




$$
\begin{aligned}
\frac{\partial \nabla^{2} \chi_{\mathrm{o}}}{\partial \mathrm{t}}= & -\mathrm{J}\left(\chi_{\mathrm{o}}, \nabla^{2} \psi_{\mathrm{o}}+2 \mu+\frac{1}{2} \mathrm{~h}_{\mathrm{o}}\right)-\nabla \cdot\left[\left(\nabla^{2} \psi_{\mathrm{o}}+2 \mu+\frac{1}{2} \mathrm{~h}_{\mathrm{o}}\right) \nabla \tau_{\mathrm{o}}\right] \\
& -\nabla \cdot\left[\left(\nabla^{2} \tau_{\mathrm{o}}-\frac{1}{2} \mathrm{ho}\right) \nabla \psi \mathrm{o}\right]+\mathrm{K}_{6} \nabla^{8} \chi_{\mathrm{o}}-\frac{\mathrm{k}_{2}}{2(\Delta z)^{2}} \nabla^{2} \chi_{\mathrm{o}} \\
& +\nabla^{2}\left[\nabla \psi_{\mathrm{o}} \cdot \nabla \tau_{\mathrm{o}}-\mathrm{J}\left(\psi_{\mathrm{o}}, \chi_{\mathrm{o}}\right)+\mathrm{B}_{\mathrm{o}} \theta_{\mathrm{o}}\right]-\frac{\mathrm{p}_{\mathrm{o}} \mathrm{K}}{4 \rho_{\mathrm{o}} g \Delta z} \nabla^{2} \chi \\
\frac{\partial \theta_{\mathrm{o}}}{\partial \mathrm{t}}= & -\mathrm{J}\left(\psi_{\mathrm{o}}, \theta_{\mathrm{o}}\right)-\mathrm{J}\left(\tau_{\mathrm{o}}, \sigma_{\mathrm{o}}\right)+\nabla \cdot \sigma_{\mathrm{o}} \nabla \chi_{\mathrm{o}}+\mathrm{K}_{6} \nabla^{6} \theta_{\mathrm{o}}-\mathrm{H}_{\mathrm{o}} \\
& +\mathrm{k}_{2} \frac{\sigma_{\mathrm{o}}-\theta_{\mathrm{o}}+\sqrt{2} \theta_{\mathrm{o}}^{\mathrm{a}}}{4(\Delta z)^{2}} \\
\frac{\partial \sigma_{\mathrm{o}}}{\partial \mathrm{t}}= & -\mathrm{J}\left(\psi_{\mathrm{o}}, \sigma_{\mathrm{o}}\right)-\mathrm{J}\left(\tau_{\mathrm{o}}, \theta_{\mathrm{o}}\right)+\nabla \cdot \theta_{\mathrm{o}} \nabla \chi_{\mathrm{o}}+\mathrm{K}_{6} \nabla^{6} \sigma_{\mathrm{o}}-\mathrm{H}_{\mathrm{o}} \\
& -\mathrm{k}_{2} \frac{5 \sigma_{\mathrm{o}}-\theta_{\mathrm{o}}+\sqrt{2} \theta_{\mathrm{o}}^{\mathrm{a}}}{4(\Delta z)^{2}} .
\end{aligned}
$$

Here, the ocean basin topography is $h_{\mathrm{o}}$ and at the land-ocean boundary the topographic height difference is $150 \mathrm{~m}, \mathrm{~K}_{6}=5 \times 10^{25} \mathrm{~m}^{6} \mathrm{~s}^{-1}$ is a horizontal diffusion coefficient, $\theta_{\mathrm{o}}^{\mathrm{a}}$ is the abyssal apparent temperature, $\Delta z=50 \mathrm{~m}$ is half the depth between the two levels, $p_{o}=1000 \mathrm{hPa}$ is the surface pressure and $\mathrm{B}_{\mathrm{o}}=\alpha \Delta z \mathrm{~g}$. Also, $\mathrm{H}_{\mathrm{o}}$ represents a heating term that is related to the vertical heat flux between the ocean and atmosphere.

\subsection{Ocean-atmosphere coupling}

The coupling between the ocean and atmosphere is through the surface stresses and heat fluxes. Following Schopf and Suarez [13], the surface wind stress is assumed to be proportional to the lower level velocity. In the ocean mean and shear streamfunction, the impact of the wind stress is $p_{\mathrm{o}} K \nabla^{2}(\psi-\tau) /\left(4 \rho_{\mathrm{o}} g \Delta z\right)$; a similar term $-p_{\mathrm{o}} K \nabla^{2} \chi /\left(4 \rho_{\mathrm{o}} g \Delta z\right)$ appears in the divergence equation.

The surface heat flux $\mathrm{H}_{\theta}$ between the atmosphere and the ocean is assumed 
to be $H_{\theta}=-\gamma\left(T_{s}-T_{1}\right)$ [13], where $T_{s}$ and $T_{1}$ are the surface air temperature and first level ocean temperature, respectively, and $\gamma$ is a proportionality coefficient, assumed constant and equal to $15 \mathrm{Wm}^{-1} \mathrm{~K}^{-1}$ over the ocean basin. Temperature $T_{s}$ is linearly extrapolated from the air temperature at the two levels using the logarithm of the atmospheric pressure [13]. Therefore,

$$
\begin{aligned}
\mathrm{T}_{\mathrm{s}} & \approx 0.986 \theta-1.388 \sigma, \\
\mathrm{H}_{\theta} & \approx \gamma\left(0.986 \theta-1.388 \sigma-\theta_{\mathrm{o}}-\sigma_{\mathrm{o}}-\sqrt{2} \mathrm{~T}_{\mathrm{o}}^{*}\right), \\
\mathrm{H}_{\mathrm{o}} & =\frac{\mathrm{H}_{\theta}}{4 \rho_{\mathrm{o}} \Delta z \mathrm{c}_{\mathrm{o}}},
\end{aligned}
$$

where $c_{o}=4 \times 10^{3} \mathrm{Jkg}^{-1} \mathrm{~K}^{-1}$ is the specific heat of water. In the case of the atmosphere, the relaxation terms in equations (4)-(5) incorporate all the sources of heating associated with the annual cycle of the climatological state, including the surface heat flux. This annual cycle of climatological surface heat flux is removed from $\mathrm{H}_{\mathrm{o}}$ and only the remaining anomalous surface heat flux is applied to the atmosphere. The anomalous heat flux is

$$
\Delta \mathrm{H}_{\theta} \approx-\gamma\left[0.986\left(\theta-\theta_{\mathrm{E}}\right)-1.388\left(\sigma-\sigma_{\mathrm{E}}\right)-\theta_{\mathrm{o}}-\sigma_{\mathrm{o}}-\theta_{\mathrm{SST}}\right] .
$$

Here, $\theta_{\text {SST }}$ is the climatological annual cycle of the apparent observed seasuface temperature (SST) for the period 1981-2000, using the Reynolds SST dataset [19]. The additional heating term in equation (4) is

$$
\mathrm{H}_{\mathrm{a}}=\frac{\mathrm{g} \Delta \mathrm{H}_{\theta}}{\mathrm{p}_{\mathrm{o}} \overline{\mathrm{p}} \mathrm{c}_{\mathrm{p}}}
$$

and $\bar{p}=0.797$.

\subsection{Computational methods}

All derivatives with respect to the vertical coordinate $p$ (and $z$ ) are finite differenced in the vertical, according to

$$
\left.\frac{\partial \psi}{\partial p}\right|_{i}=\frac{\psi_{i-1}-\psi_{i+1}}{p_{i-1}-p_{i+1}} .
$$


Time differencing uses the semi-implicit technique, allowing for a larger time step,

$$
\frac{\partial \psi}{\partial t}=\frac{\psi^{\tau}+\psi^{t-1}}{\Delta t}
$$

where

$$
\psi^{\tau}=\frac{\psi^{\mathrm{t}+1}+\psi^{\mathrm{t}-1}}{\Delta \mathrm{t}}
$$

Horizontally, the atmospheric and ocean fields are expanded in spherical harmonics:

$$
\psi(\lambda, \mu, t)=\sum_{m=J}^{J} \sum_{l=m}^{|m|+J} \psi_{l}^{m}(t) P_{l}^{m}(\mu) e^{i m \lambda},
$$

where $\mathrm{P}_{l}^{\mathrm{m}}$ is the associated Legendre polynomial of the first kind. We assume that $\psi$ is real by taking complex conjugate of $\psi_{l}^{m}$ to be defined by $\psi_{l}^{m *}=$ $-\psi_{l}^{-m}$. The truncation in equation (20) is rhomboidal 31. Spectral to grid and grid to spectral transforms are used when coupling the atmosphere to the ocean component. Formulated in this way, the model conserves energy and entropy and can be run at very low viscosity even at low resolution; this is in contrast to many more complex models.

\section{Model climate and variability}

The model equations were integrated for 80 years from rest with the atmosphere and oceanic circulation spun up and allowed to equilibrate over the first five years. The model time step is 20 minutes, to avoid computational instability, and one year of simulation takes about 20 minutes of $\mathrm{CPU}$ time. Figure 1 shows the annual mean climatology over the last 75 years for the oceanic (a) $150 \mathrm{~m}$ zonal velocity and (b) $50 \mathrm{~m}$ temperature. The model has a realistic equatorial westerly current of about $1.2 \mathrm{~ms}^{-1}$, recirculating easterly flow in the eastern Pacific at $50 \mathrm{~m}$ (not shown) and western boundary currents. Similarly, the $50 \mathrm{~m}$ temperature is well represented in both magnitude and 
general distribution. The model also captures the observed climatology of the annual cycle of the atmospheric circulation. This is illustrated for the $250 \mathrm{hPa}$ zonal wind during January and July in Figure 2.

The model also has quite realistic ENso-like variability. Figure 3 shows the $50 \mathrm{~m}$ ocean temperature anomalies averaged over $5^{\circ} \mathrm{S}$ to $5^{\circ} \mathrm{N}$ for the last 70 years of integration. Anomalous fluctuations between $-4 \mathrm{~K}$ to $+4 \mathrm{~K}$ occur periodically throughout the 70 years, with the largest magitude in the eastern Pacific. To investigate the range of frequencies in these fluctuations, we performed a wavelet analysis [20] using an ENSO index defined as the area averaged $50 \mathrm{~m}$ ocean temperature anomaly between $160^{\circ} \mathrm{W}$ to $80^{\circ} \mathrm{W}$ and $5^{\circ} \mathrm{S}$ to $5^{\circ} \mathrm{N}$. The result is shown in Figure 4 for frequency (in units per month) versus year. Clearly, the model displays variability at different time scales over the period, including in the two to three year, four to five year, seven to eight year and decadal ranges.

To investigate the dominant modes of variability of the $50 \mathrm{~m}$ temperature variability, we performed a principal oscillation pattern (POP) analysis [21]. Figure 5 shows the imaginary and real parts of a POP with period 28 months. The imaginary and real parts are a quarter period out of phase and are remarkably similar to the first and second empirical orthogonal functions (EOFs) [22] (not shown) which explains $26.9 \%$ and $10.9 \%$ of the intermonth variance, respectively, in the $50 \mathrm{~m}$ ocean temperature. The imaginary part (or first EOF) has ENSO characteristics with large (positive) weighting along the equator near $140^{\circ} \mathrm{W}$; off the equator and in the west Pacific there are negative loadings. The real part (or second EOF) has a tri-pole structure with largest magnitude near the dateline. Taken together, the real and imaginary EOF describe the evolution of the temperature anomaly over the life cycle of the mode. 
(a)

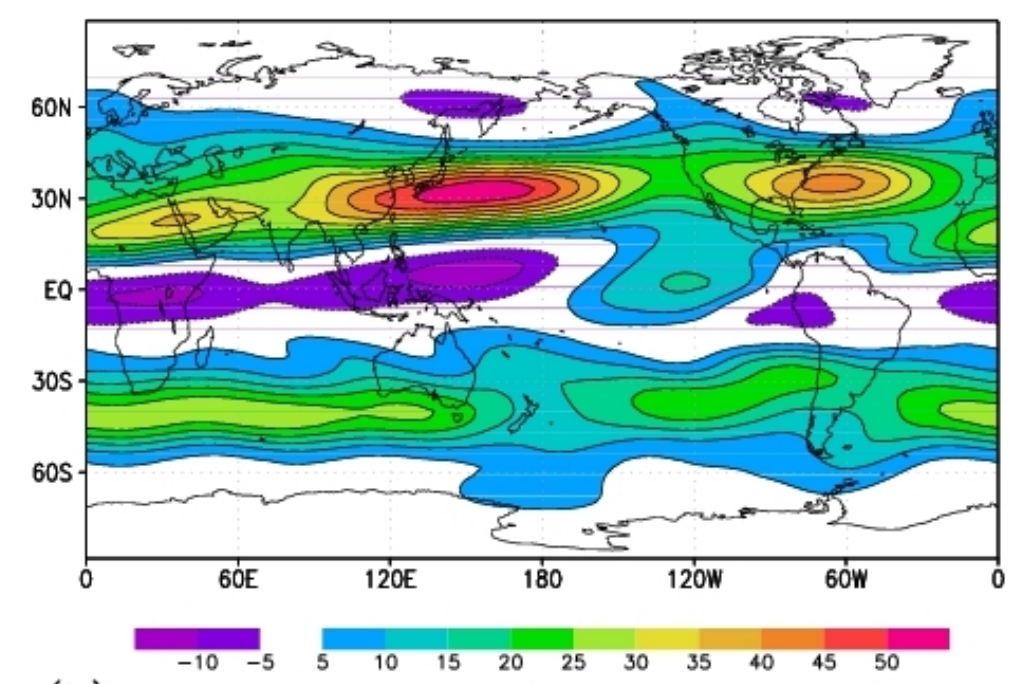

(b)

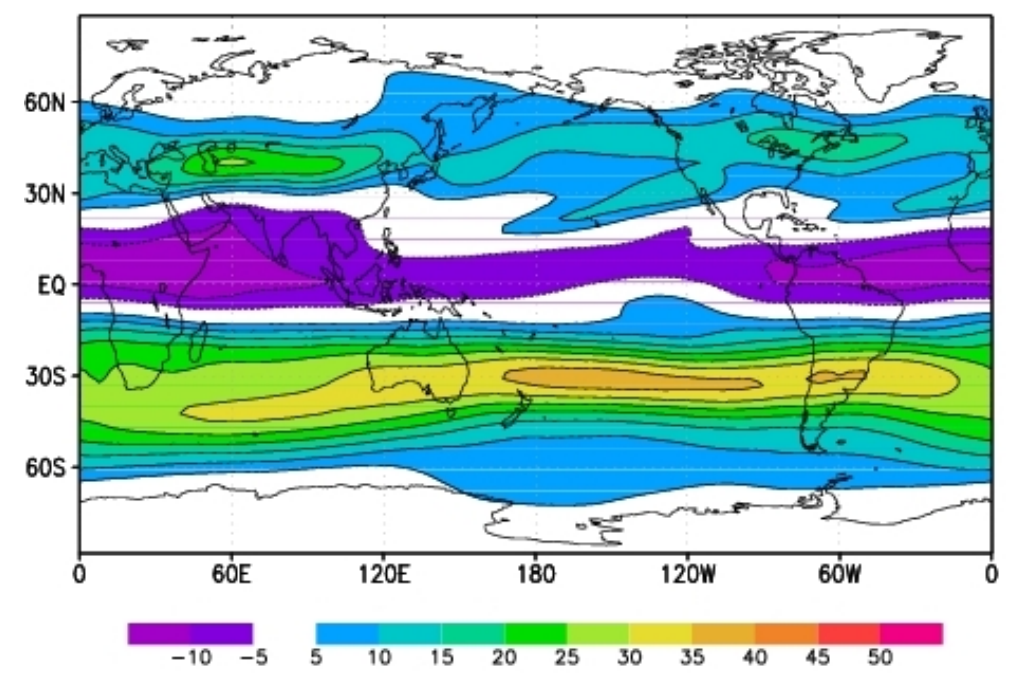

Figure 2: Atmosphere climatology for $250 \mathrm{hPa}$ zonal velocity during (a) January and (b) July. 


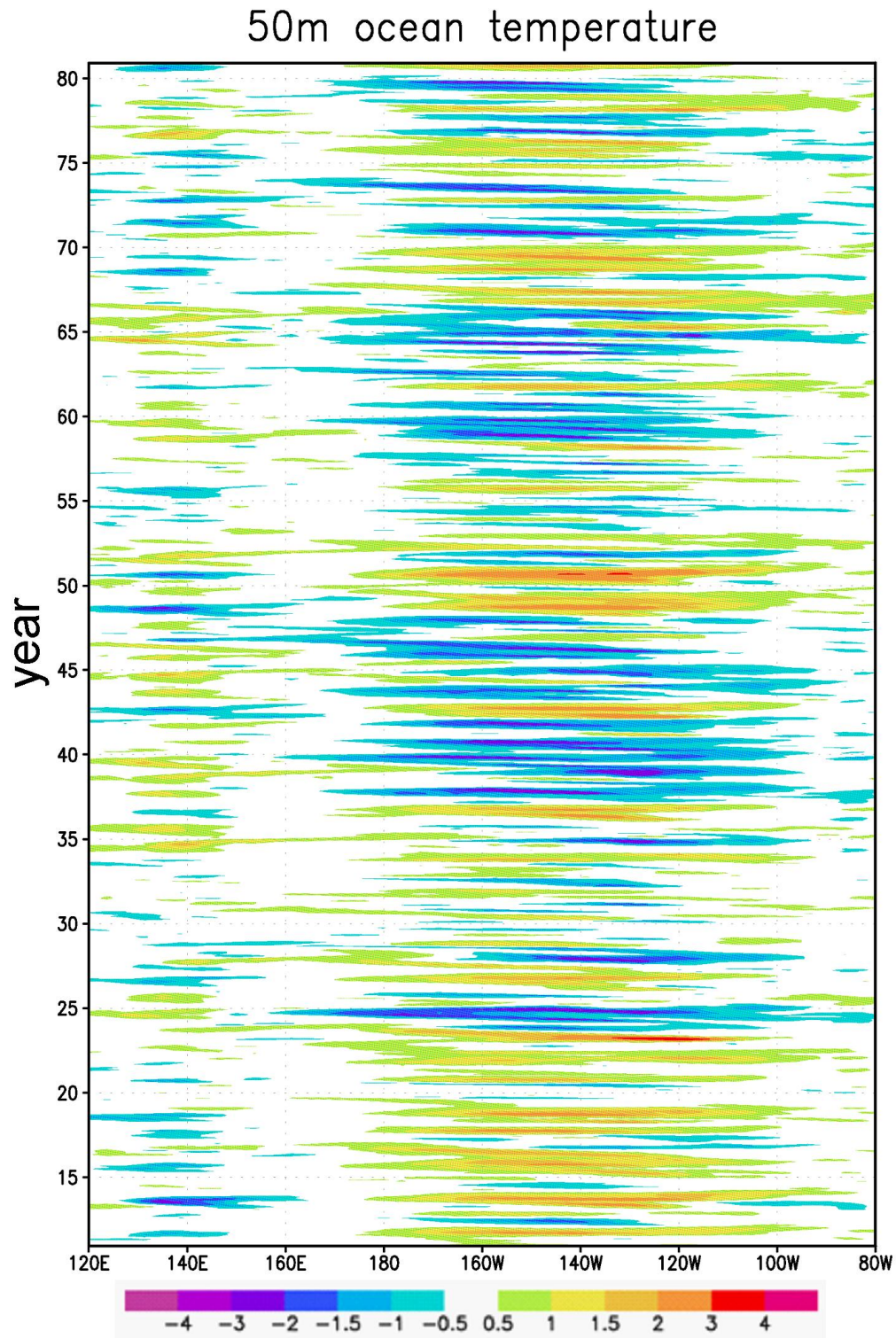

Figure 3: Evolution of $50 \mathrm{~m}$ ocean temperature anomalies averaged over $5^{\circ} \mathrm{S}$ to $5^{\circ} \mathrm{N}$. 


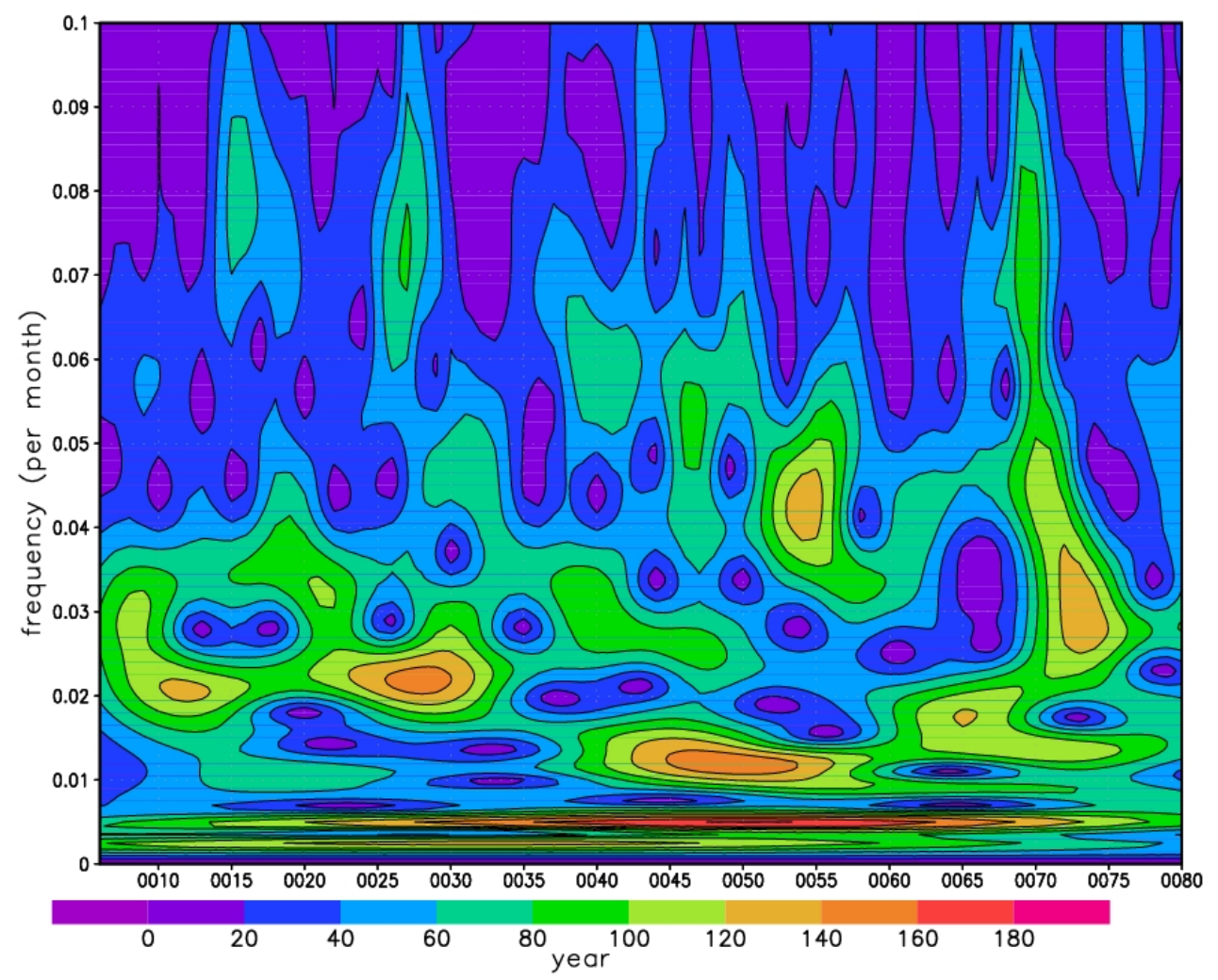

Figure 4: Wavelet analysis using an ENSO index of $50 \mathrm{~m}$ ocean temperature.

\section{Model predictive skill}

The model has a good climatology and ENSO-like variability, so it is interesting to evaluate whether it has any predictive skill in forecasting the variability and regime transitions associated with ENSO, especially over the tropical Pacific. For this purpose, twelve month forecasts have been initialised each month for the period January 1981 to December 2000. These forecasts are initialised from an analysis run where the model's ocean temperature at $50 \mathrm{~m}$ and $150 \mathrm{~m}$ 


\section{(a)}

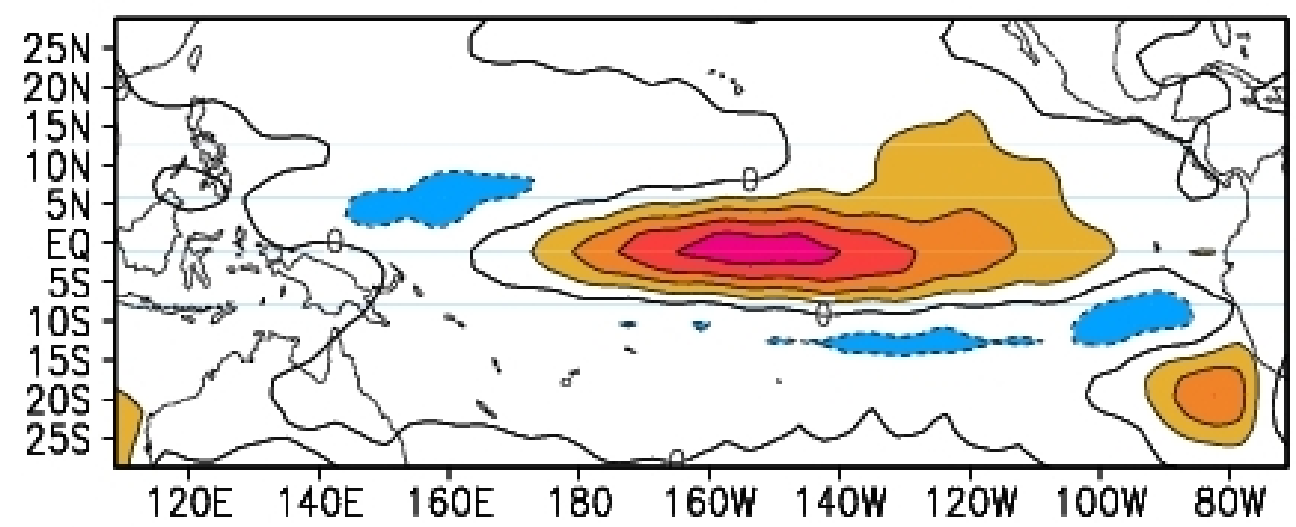

(b)
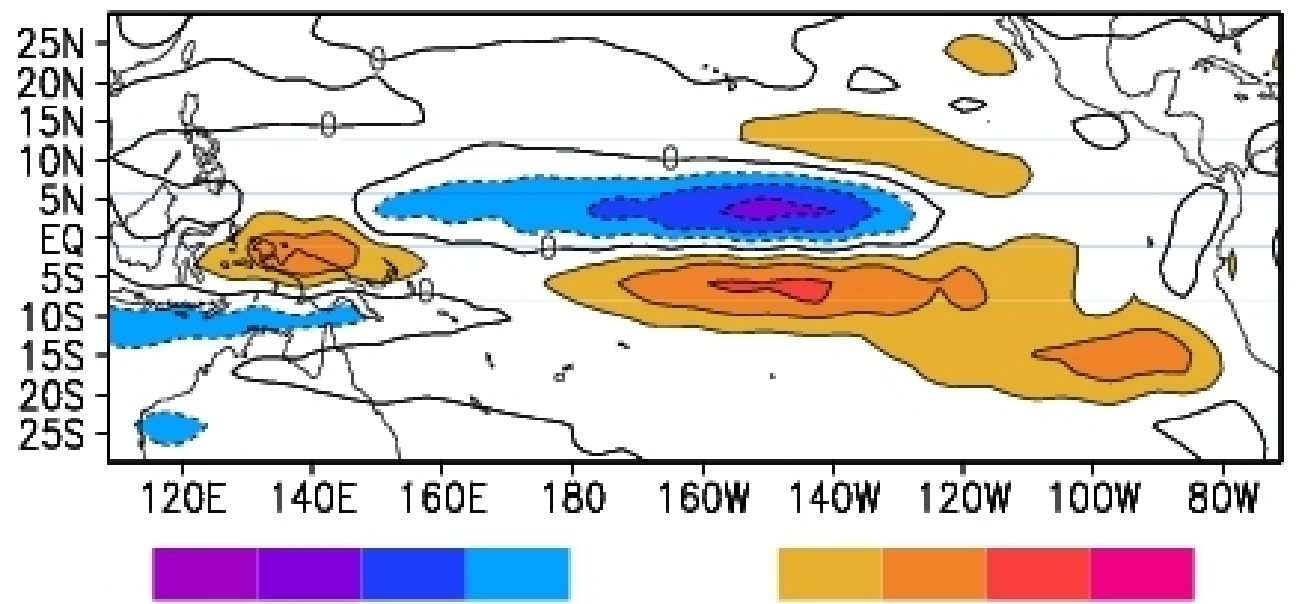

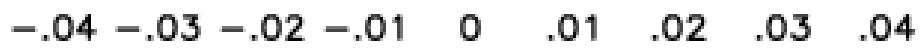

Figure 5: The (a) imaginary and (b) real components of a propagating model ENSO mode (POP) associated with the dominant mode of $50 \mathrm{~m}$ ocean temperature variability. 
and surface wind stress anomalies are nudged to the observed in the following manner:

$$
\Delta f_{\text {nudge }}=(1-\omega) \Delta f_{\text {model }}+\omega \Delta f_{\text {obs }} .
$$

Here, $\Delta f_{\text {model }}, \Delta f_{\text {obs }}, \Delta f_{\text {nudge }}$ represent the model, observed and nudged anomalies, and $\omega$ is some weight (taken to be 0.5 in the tropics and 0.75 in the extratropics).

The focus is mainly on the model's ability to forecast the $50 \mathrm{~m}$ ocean temperature and zonal velocity over the tropical domain $130^{\circ} \mathrm{E}$ to $80^{\circ} \mathrm{W}$ and $10^{\circ} \mathrm{S}$ to $10^{\circ} \mathrm{N}$. Figure $6(\mathrm{a}, \mathrm{b})$ shows the anomaly correlation pattern (APC) for the ocean temperature and zonal velocity, respectively, while Figure $6(\mathrm{c}, \mathrm{d})$ show the corresponding area averaged root-mean-square (RMS) error for each field. The model is able to capture the horizontal structure of the temperature and zonal velocity over this period. Thus, for example, the model forecasts for these fields have APCs greater than or equal to 0.6 out to seven months during the major 1982/83 and 1997/98 El Niños and the 1988/89 La Niña, once the ocean anomaly is in the rapidly growing phase. During these major transitions, the model also displays quite large error growth, see Figure 6(c,d), prior to the establishment of the event. Generally the largest RMS errors occur for the forecasts initiated between January and May, while the forecasts initiated between June and November have the largest APC with skill out to seven months. For the weaker El Niño events (1986/87, 1991/92, 1994/95) and La Niña events $(1984 / 85,1995 / 96,1999 / 2000)$, the model displays good skill $($ APC $\geqslant 0.6)$ out to five months ahead.

The skill in forecasting the atmospheric fields (not shown) is mainly limited to the first month, although during the major ENSO events good skill can be extended out to three months. 
50m Temperature

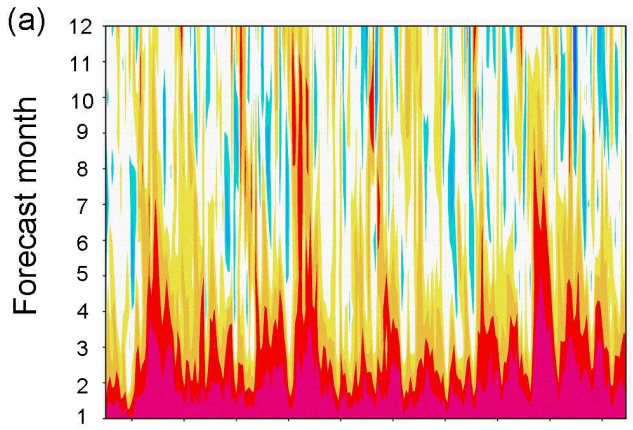

1982198419861988199019921994199619982000

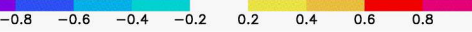
year

(b)

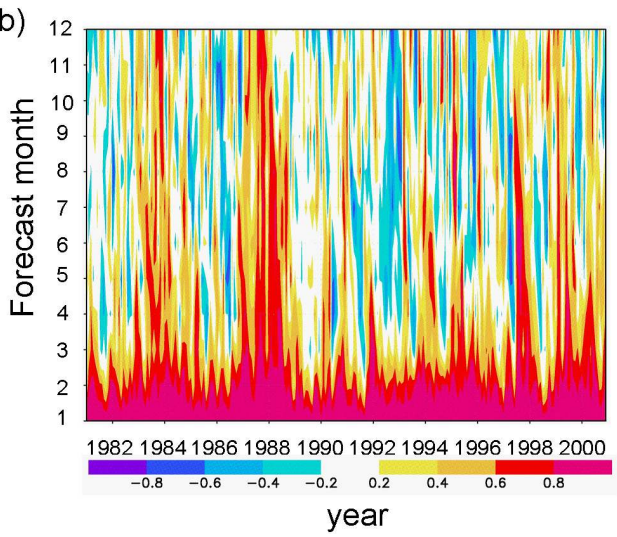

(c)

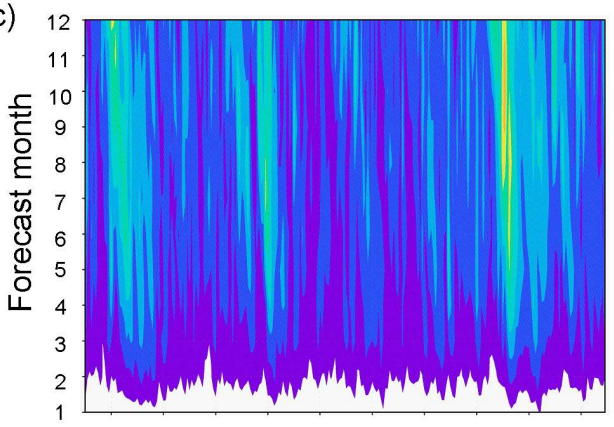

1982198419861988199019921994199619982000

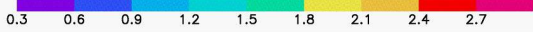
year

(d)

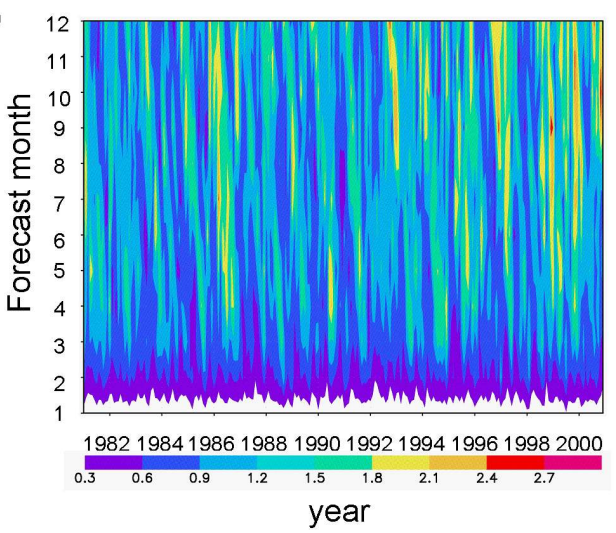

Figure 6: The anomaly pattern correlation and root mean square error; for forecasts of $50 \mathrm{~m}$ ocean temperature, (a) and (c); and zonal velocity, (b) and (d). 


\section{Conclusions}

We formulated a numerically efficient and energy conserving coupled oceanatmosphere model with just two levels, and with ten prognostic equations describing the dynamics and thermodynamics of the coupled system. While the atmosphere is global, the ocean consists of a hemispheric Pacific basin. As a low resolution model, it has a good climatology and variability in both the ocean and atmosphere. In particular, it displays ENSO-like variability over periods associated with this major coupled variability over the Pacific Ocean, comparable to more complex and higher resoution models. The model also has good forecast skill, especially for the $50 \mathrm{~m}$ ocean temperature and zonal velocity, with skill out to seven months during major ENSO events. Being a low resolution model, it is very efficient and economical to run, completing multi-decadal simulations or forecasts at the rate of 20 minutes of CPU per year of simulation. This is not possible with more complex and higher resolution models and makes the model introduced here an ideal research tool for testing out new ideas, for example, in developing new strategies for ensemble seasonal prediction.

\section{References}

[1] S. G. H. Philander, El Niño, La Niña and the Southern Oscillation. Academic Press, San Diego. 293pp, 1990. C35

[2] C. S. Frederiksen and X. Zheng, Variability of seasonal-mean fields arising from intraseasonal variability: Part 2, Application to $\mathrm{NH}$ winter circulations, Clim. Dyn.,23, 193-206, 2004. doi:10.1007/s00382-004-0429-6 C35

[3] C. S. Frederiksen and X. Zheng, Variability of seasonal-mean fields arising from intraseasonal variability: Part 3, Application to $\mathrm{SH}$ winter 
and summer circulations, Clim. Dyn.,28, 849-866, 2007. doi:10.1007/s00382-006-0214-9 C35

[4] C. F. Ropelewski and M. S. R. Halpert, Global and regional scale precipitation patterns associated with the El Niño/Southern Oscillation, Mon. Wea. Rev.,115, 1606-1626, 1987. doi:10.1175/1520-0493(1987)115<1606:GARSPP > 2.0.CO;2 C35

[5] N. E. Graham, J. Michaelson, T. P. Barnett, T.P., An investigation of the El Niño-Southern Oscillation cycle with statistical models: II. Model results. J. Geophys. Res., 92, 14271-14289, 1987. doi:10.1029/JC092iC13p14271 C35

[6] M. A. Cane and S. E. Zebiak, A theory for El Niño and the Southern Oscillation. Science, 228, 1085-1087, 1985. doi:10.1126/science.228.4703.1085 C35

[7] D. S. Battisti and A. C. Hirst, Interannual variability in the tropical atmosphere-ocean system: influence of the basic state, ocean geometry, and non-linearity. J. Atmos. Sci., 46, 1687-1712, 1989. doi:10.1175/1520-0469(1989)046<1687:IVIATA > 2.0.CO;2 C35

[8] R. Kleeman, On the dependence of hindcast skill on ocean thermodynamics in a coupled ocean-atmosphere model. J. Climate., 6 , 2012-2033, 1993. doi:10.1175/1520-0442(1993)006<2012:OTDOHS > 2.0.CO;2 C35

[9] J. D. Neelin and H. A. Dilkstra, Ocean-atmosphere interaction and the tropical climatology. Part I:the dangers of flux correction. J. Climate., 8, 1325-1342, 1995. doi:10.1175/1520-0442(1995)008< < 1325:OAIATT > 2.0.CO;2 C35

[10] M. Latif, K. Sperber, J. Arblaster, P. Braconnot, D. Chen, A. Colman, U. Cubasch, C. Cooper, P. Delecluse, D. Dewitt, L. Fairhead, G. Flato, T. Hogan, M. Ji, M. Kimoto, A. Kitoh, T. Knutson, H. Le Treut, T. Li, S. Manabe, O. Marti, C. Mechoso, G. Meehl, S. Power, E. Roeckner, J. 
Sirven, L. Terray, A. Vintzileos, R. Voss, B. Wang, W. Washington, I. Yoshikawa, J. Yu and S. Zebiak, ENSIP: the El Niño simulation intercomparison project. Clim. Dyn., 18, 255-276, 2001. doi:10.1007/s003820100174 C35

[11] A. Rosati, K. Miyakoda, and R. Gudgel, The impact of ocean initial conditions on ENSO forecasting with a coupled model. Mon. Weath. Rev., 125, 754-772, 1997. doi:10.1175/1520-0493(1997)125<0754:TIOOIC>2.0.CO;2 C35

[12] B. P. Kirtman, J. Shukla, B. Huang, Z. Zhu and E. K. Schneider, Multi-seasonal prediction with a coupled tropical ocean global atmosphere system. Mon. Weath. Rev., 125, 789-808, 1997. doi:10.1175/1520-0493(1997)125<0789:MPWACT>2.0.CO;2 C35

[13] P. S. Schopf and M. J. Suarez, Vacillations in a coupled ocean-atmosphere model. J. Atmos. Sci., 45, 549-566, 1988. doi:10.1175/1520-0469(1988)045<0549:VIACOM > 2.0.CO;2 C35, C41, $\mathrm{C} 42$

[14] T. N. Palmer, A. Alessandri, U. Andersen, P. Cantelaube, M. Davey, P. De-lecluse, M. Deque, E. Diez, F. J. Doblas-Reyes, H. Feddersen, R. Graham, S. Gualdi, J.-F. Gueremy, R. Hagedorn, M. Hoshen, N. Keenlyside, M. Latif, A. Lazar, E. Maisonnave, V. Marletto, A. Morse, B. Orfila, P. Rogel, J.-M. Terres and M. C. Thomson, Development of a European multi-model ensemble system for seasonal to interannual prediction (DEMETER). Bull. Am. Met. Soc., 85, 853-872, 2004. doi:10.1175/BAMS-85-6-853 C35

[15] E. K. Jin, J. L. Kinter, B. Wang, C.-K. Park, I.-S. Kang, B. P. Kirtman, J.-S. Kug, A. Kumar, J.-J. Luo, J. Schemm, J. Shukla, and T. Yamagata, Current status of ENSO prediction skill in coupled ocean-atmo- sphere models. Clim. Dyn., 31, 647-664, 2008. doi:10.1007/s00382-008-0397-3 C36 
[16] B. Wang, J.-Y. Lee, I.-S. Kang, J. Shukla, J.-S. Kug, A. Kumar, A., J. Schemm, J.-J. Luo, T. Yamagata, T. and C.-K. Park, How accurately do coupled climate models predict the leading modes of Asian-Australian Monsoon interannual variability? Clim. Dyn., 30, 2008, 605-10. doi:10.1007/s00382-007-0310-5 C36

[17] J. S. Frederiksen, C. S. Frederiksen and S. L. Osbrough. Methods of ensemble prediction for seasonal forecasts with a coupled ocean-atmosphere model. ANZIAM J., submitted. C36

[18] D. Levitus, Climatological atlas of the world ocean. NOAA/ERL GFDL Professional Paper 13. Princeton, N.J., 173pp, 1982 (NTIS PB83184093). C40

[19] R. W. Reynolds and T. M. Smith, Improved Global Sea Surface Temperature Analyses Using Optimum Interpolation, J. Climate,7, 929-948, 1994. doi:10.1175/1520-0442(1994)007<0929:IGSSTA > 2.0.CO;2 C42

[20] C. Torrence and G. P. Compo, A Practical Guide to Wavelet Analysis, Bull. Am. Met. Soc.,79, 61-78, 1998. doi:10.1175/1520-0477(1998)079<0061:APGTWA > 2.0.CO;2 C44

[21] K. F. Hasselmann, PIPs and POPs: The reduction of complex dynamical systems using Principal Interaction and Oscillation Patterns, J. Geophys. Res.,93, 11015-11021, 1988. doi:10.1029/JD093iD09p11015 $\mathrm{C} 44$

[22] I. T. Jolliffe, Principal Component Analysis. Springer Verlag. 271pp, 1986. C44

\section{Author addresses}

1. C. S. Frederiksen, Centre for Australian Weather and Atmospheric Research, Bureau of Meteorology, Melbourne, Victoria 3001, Australia. 
mailto:c.frederiksen@bom.gov.au

2. J. S. Frederiksen, Climate Adaptation Flagship, Centre for Australian Weather and Atmospheric Research, CSIRO Marine and Atmospheric Research, Aspendale, Victoria 3195, Australia.

3. R. C. Balgovind, Bureau of Meteorology, Melbourne, Victoria 3001, Australia. 